\title{
PENGARUH CAR, NPL, BOPO, NIM \\ DAN LDR TERHADAP ROA \\ (Studi kasus pada Bank Perkreditan Rakyat di Salatiga yang terdaftar di \\ Otoritas Jasa Keuangan Tahun 2011-2015)
}

\author{
Oleh : \\ Erna Sudarmawanti \\ Dosen Tetap STIE AMA Salatiga \\ Joko Pramono \\ Dosen Tetap STIE AMA Salatiga
}

\begin{abstract}
Abstrak
Masalah dalam penelitian ini Apakah CAR, NPL, BOPO, NIM dan LDR secara baik partial maupun simultan berpengaruh terhadap ROA (studi kasus pada Bank Perkreditan Rakyat di Salatiga yang terdaftar di Otoritas Jasa Keuangan Tahun 2011-2015)? Tujuan penelitian untuk mengetahui Apakah CAR, NPL, BOPO, NIM dan LDR secara partial maupun simultan berpengaruh terhadap ROA. Penelitian ini menggunakan data sekunder, yaitu laporan keuangan dari tahun 2011-2015 dari Bank Perkreditan Rakyat yang terdaftar di Otoritas Jasa Keuangan. Analisis datanya menggunakan analisis regresi linier berganda.

Hasil analisis diperoleh persamaan $Y=57,485-0,050 X_{1}-0,259 X_{2}-0.087$ $X_{3}+0,064 X_{4}-0,229 X_{5}$. Berdasarkan persamaan tersebut diperoleh thitung untuk variabel CAR sebesar -1,613 (Sig.0,129) artinya CAR tidak mempunyai pengaruh yang signifikan terhadap ROA. Nilai t hitung variabel NPL sebesar -2,230 (Sig.0,043) artinya NPL mempunyai pengaruh yang signifikan terhadap ROA. Nilai $t$ hitung variabel BOPO sebesar -5,774 (Sig.0,000) artinya BOPO mempunyai pengaruh yang signifikan terhadap ROA. Nilai thitung variabel NIM sebesar 0,78 (Sig.0,467) artinya NIM tidak mempunyai pengaruh yang signifikan ROA. Nilai t hitung variabel LDR sebesar-2,752 (Sig.0,016) artinya LDR -2,752 (Sig.0,016) artinya LDR mempunyai pengaruh yang signifikan terhadap ROA. Pengujian simultan nilai $F$ hitung sebesar 10,824 (Sig.0,000) sedangkan nilai $F$ tabel dengan degreeof freedom (df) pada angka 5 dan 14, level significance 0,05 sebesar 2,39 sehingga nilai $F$ hitung $=10,824$ jauh lebih besar daripada $F$ tabel 2,96 dan signifikansi (0,000) lebih kecil dari 0,05 maka model regresi dapat digunakan untuk memprediksi variabel ROA atau dapat dikatakan bahwa tingkat CAR (X1), NPL (X2), BOPO (X3), NIM (X4) dan LDR (X5) secara bersama-sama berpengaruh terhadap ROA $(Y)$.

Kesimpulan dari penelitian adalah CAR (X1), NPL (X2), BOPO (X3), NIM (X4) dan LDR (X5) secara partial CAR (X1) dan NIM (X4) tidak berpengaruh secara signifikan terhadap ROA (Y), sedangkan NPL (X2), BOPO (X3) dan LDR (X5) berpengaruh signifikan terhadap ROA $(Y)$. Secara simultan kelima variabel berpengaruh terhadap ROA $(Y)$.
\end{abstract}

Kata Kunci : CAR, NPL, BOPO, NIM, LDR, ROA

Analisis Pengaruh CAR, NPL, BOPO, NIM

dan LDR Terhadap ROA (Studi Kasus Pada Bank Perkreditan Rakyat di Salatiga

yang Terdaftar Di Otoritas Jasa Keuangan Tahun 2011-2015).

(Erna Sudarmawanti, Joko Pramono) 


\section{PENDAHULUAN}

Perekonomian yang cepat tumbuh membuat lebih banyak pula modal yang diperlukan untuk selalu meningkatkan perekonomian suatu negara. Perlu suatu perusahaan bergerak di bidang jasa yang menyediakan jasa keuangan bagi seluruh lapisan masyarakat, dan perusahaan tersebut dikenal dengan nama bank. Fungsi utama bank secara umum adalah menghimpun dana dari masyarakat dan menyalurkan kembali pada masyarakat untuk berbagai tujuan oleh karena itu kepercayaan dari masyarakat menjadi faktor yang utama dalam menjalankan bisnis perbankan dan bank umum menjadi sangat penting pada masyarakat umum.

Krisis moneter yang terus menerus mengakibatkan krisis kepercayaan, akibatnya banyak bank lumpuh. Dampak yang muncul akibat kegagalan usaha bank menimbulkan perlunya dilakukan serangkaian analisis yang sedemikian rupa sehingga resiko kegagalan bank dapat dideteksi sedini mungkin, salah satu caranya adalah dengan melihat kinerja perbankan. Menilai suatu kinerja lembaga keuangan sangatlah penting. Penilaian untuk menentukan kondisi suatu bank biasanya menggunakan alat ukur. Bank Indonesia melakukan otoritas moneter menetapkan ketentuan standarisasi kemampuan menghasilkan pendapatan. Peningkatan pendapatan atau keuntungan dari total aktiva yang dimiliki oleh bank dapat menggambarkan kondisi bank dan kemampuan pengelolaannya.

Bank yang sehat adalah bank yang diukur secara rentabilitas yang terus meningkat. Ini juga berkaitan dengan efisiensi dan kemampuan bank dalam melakukan kegiatan operasi, dengan adanya efisiensi biaya maka keuntungan yang diperoleh bank akan semakin besar. Sementara kinerja yang diperlihatkan perbankan dengan melihat indikator keuangan sangat menentukan kinerja bank tersebut. Kinerja keuangan perbankan dapat dilihat dari beberapa indikator keuangan seperti CAR (Capital Adequacy Ratio) yang merupakan sebagai kecukupan pemenuhan KPMM (Kewajiban Penyediaan Modal Minimum) sesuai ketentuan yang berlaku. BOPO sebagai suatu indikator rentabilitas perbankan. LDR (Loan Deposit Ratio) untuk menunjukkan sebagai indikator likuiditas perbankan. Termasuk juga ROA (Return On Assets) serta NIM (Net Interest Margin). 
Hasil yang diperoleh akan menggambarkan kondisi bank umum dan kemampuan pengelolaannya. Misalnya bank yang memiliki ROA yang semakin tinggi dapat dikatakan semakin efisien, karena tingkat pertambahan laba meningkatkan pertumbuhan aset. Dengan melihat indikator tingkat kesalahan suatu bank kita dapat mengetahui pengaruh terhadap kinerja perbankan itu sendiri, sehingga memberikan probalilitas secara keseluruhan baik bagi bank tersebut serta dunia perbankan Indonesia. Pemerintah pada dasarnya sudah berupaya untuk memperbaiki kinerja perbankan nasional agar tidak membahayakan kelangsungan usahanya.

Berdasarkan uraian latar belakang di atas, maka penulis merasa tertarik untuk melakukan penelitian dengan judul Analisa Pengaruh CAR, NPL, BOPO, NIM dan LDR Terhadap ROA (Studi Kasus pada Bank Perkreditan Rakyat di Salatiga yang terdaftar di Otoritas Jasa Keuangan Tahun 2011-2015)

\section{RUMUSAN MASALAH}

Berdasarkan latar belakang diatas, maka dapat dirumuskan masalah menjadi, apakah CAR, NPL, BOPO, NIM, dan LDR berpengaruh terhadap ROA (Return On Assets) pada Bank Perkreditan Rakyat di Salatiga yang terdaftar di Otoritas Jasa Keuangan Tahun 2011-2015?

\section{PAPARAN TEORITIS DAN HIPOTESIS}

Menurut Undang-undang Nomor 7 tahun 1992 tentang Perbankan sebagaimana telah diubah dengan Undang-undang nomor 10 tahun 1998 pengertian bank adalah badan usaha yang menghimpun dana dari masyarakat dalam bentuk simpanan dan menyalurkannya kepada masyarakat dalam bentuk kredit dan atau bentuk-bentuk lainnya dalam rangka meningkatkan taraf hidup rakyat banyak. Sedangkan Bank Umum adalah bank yang dapat memberikan jasa dalam lalu lintas pembayaran. Seperti diketahui bahwa fungsi bank pada umumnya :

a. Agent of trust, bank merupakan lembaga yang landasannya adalah kepercayaan, baik dalam menghimpun dana ataupun dalam penyaluran dana

b. Agent of development, Kegiatan bank berupa menghimpun dan menyalurkan dana merupakan hal yang sangat diperlukan bagi lancarnya perekonomian di sector riil. Kegiatan bank tersebut memungkinkan 
masyarakat untuk melakukan investasi, kegiatan distribusi serta kegiatan konsumsi barang dan jasa, mengingat kegiatan tersebut tidak dapat dilepaskan dari adanya penggunaan uang.

c. Agent of services yaitu bank merupakan lembaga yang meobilisasi dana untuk pembangunan ekonomi. Bank memberikan jasa perbankan yang lain kepada masyarakat. Jasa tersebut antara lain berupa jasa pengiriman uang, penitipan surat berharga, pemberian jaminan bank, dan penyelesaian tagihan.

Kegiatan usaha bank umum yang dapat dilakukan oleh bank umum menurut UU No.7 Tahun 1992 sebagaimana telah diubah dengan UU No.10 Tahun 1998 tentang Perbankan adalah sebagai berikut :

a. Menghimpun dana dari masyarakat.

b. Memberikan kredit

c. Menerbitkan surat pengakuan hutang

d. Membeli, menjual, atau menjamin surat-surat atas risiko maupun untuk kepentingan dan atas perintah nasabahnya.

e. Memindahkan uang, baik untuk kepentingan sendiri maupun kepentingan nasabahnya,dll.

\section{Capital Adequacy Ratio (CAR)}

Menurut Dendawijaya (2001), CAR adalah rasio yang memperlihatkan seberapa jauh seluruh aktiva bank yang mengandung rasio yang memperlihatkan seberapa jauh seluruh aktiva bank yang mengandung risiko (kredit, penyertaan surat berharga, tagihan pada bank lain) ikut dibiayai dari danamodal sendiri bank disamping memperoleh dana-dana dari sumbersumber diluar bank, seperti dana masyarakat, pinjaman (utang), dan lain-lain. Dengan kata lain, CAR adalah rasio kinerja bank untuk mengukur kecukupan modal yang dimiliki bank untuk menunjang aktiva yang mengandung atau menghasilkan risiko, misalnya kredit yang diberikan. CAR menunjukkan sejauhmana penurunan asset bank yang masih dapat ditutup oleh equity bank yang tersedia, semakin tinggi CAR maka semakin baik kondisi bank. Semakin besar Capital Adequacy Ratio (CAR) maka keuntungan bank juga semakin besar. Dengan kata lain, semakin kecil risiko suatu bank maka semakin besar 
keuntungan yang diperoleh bank. Menurut Mulyono (1999) CAR adalah rasio yang menunjukkan sampai sejauh mana kemampuan permodalan suatu bank untuk mampu menyerap resiko kegagalan kredit yang mungkin terjadi sehingga semakin tinggi angka rasio ini, maka menunjukkan bank tersebut semakin sehat begitu juga dengan sebaliknya.

H1: CAR berpengaruh terhadap Return On Asset (ROA)

\section{Pengaruh Non Performing Loan (NPL)}

Rasio NPL menunjukkan kemampuan manajemen bank dalam mengelola kredit bermasalah yang diberikan oleh bank. Apabila suatu bank kondisi NPL tinggi maka akan memperbesar biaya lainnya, sehingga berpotensi terhadap kerugian bank (Mawardi, 2005). Semakin tinggi rasio NPL maka semakin buruk kualitas kredit yang menyebabkan jumlah kredit bermasalah semakin besar sehingga dapat menyebabkan kemungkinan suatu bank dalam kondisi bermasalah semakin besar. Setelah kredit diberikan, bank wajib melakukan pemantauan terhadap penggunaan kredit serta kemampuan dan kepatuhan debitur dalam memenuhi kewajiban. Bank melakukan peninjauan penilaian dan pengikatan terhadap agunan untuk memperkecil resiko kredit (Ali, 2004). Maka dalam hal ini semakin tinggi rasio NPL maka semakin rendah profitabilitas suatu bank.

H2: NPL berpengaruh terhadap Return On Asset (ROA)

\section{BOPO}

BOPO merupakan rasio antara biaya operasi terhadap pendapatan operasi. Menurut Sri S, dkk (2000) bank sebagai agent of trust, agent of development, serta agent of services, maka salah satu kegiatan bank adalah memberikan pelayanan jasa kepada masyarakat dan menghimpun dan menyalurkan dana. Biaya operasional digunakan untuk mengukur tingkat efisien dan kemampuan bank dalam melakukan kegiatan operasionalnya. Biaya operasional merupakan biaya yang dikeluarkan oleh bank dalam rangka menjalankan aktivitas usaha pokoknya (seperti biaya bunga, biaya tenaga kerja, biaya pemasaran dan biaya operasi lainnya).pendapatan operasional merupakan pendapatan utama bank, yaitu pendapatan bunga yang diperoleh dari penempatan dana dalam bentuk kredit dan pendapatan operasi lainnya. Semakin kecil rasio ini berarti semakin 
efisien biaya operasional yang dikeluarkan bank yang bersangkutan sehingga kemungkinan suatu bank dalam kondisi bermasalah semakin kecil. Sehingga dapat disusun suatu logika bahwa variabel efisiensi operasi yang diproksikan dengan BOPO berpengaruh negatif terhadap kinerja perbankan yang diproksikan dengan Return on Assets (ROA).

H3: BOPO berpengaruh terhadap Return On Asset (ROA)

\section{Pengaruh Net Income Margin (NIM) terhadap Return On Asset (ROA).}

Net Income Margin (NIM) merupakan rasio yang menunjukkan kemampuan manajemen bank dalam mengelola aktiva produktifnya untuk menghasilkan pendapatan bunga bersih. Pendapatan bunga bersih diperoleh dari pemberian kredit atau pinjaman, sementara bank memiliki kewajiban beban bunga kepada deposan. Semakin besar rasio ini maka meningkatkan pendapatan bunga atas aktiva produktif yang dikelola bank sehingga kemungkinan suatu bank dalam kondisi bermasalah semakin kecil. Sehingga dapat disimpulkan bahwa semakin besar perubahan Net Income Margin (NIM) suatu bank, maka semakin besar pula profitabilitas bank tersebut, yang berarti kinerja keuangan tersebut semakin meningkat. Menurut Tainio (2000), Lenz mengidentifikasikan ada enam faktor yang menentukan kinerja organisasi yaitu:

1. Properties of the environment (yang meliputi struktur pasardan posisi persaingan dari unit bisnis)

\section{Environment}

3. Organization Structure

4. Strategy

5. Market Condition

6. Quality of Management

Semakin besar rasio ini maka akan meningkatkan pendapatan bunga atas aktiva produktif yang dikelola bank, sehingga kemungkinan suatu bank dalam kondisi bermasalah semakin kecil dan kinerja perbankan tersebut akan semakin baik (Almilia dan Herdiningtyas, 2005).

H4: NIM berpengaruh terhadap Return On Asset (ROA) 


\section{Loan Deposit Ratio (LDR)}

Loan Deposit Ratio (LDR) yaitu menunjukkan kemampuan suatu bank di dalam menyediakan dana kepada debiturnya dengan modal yang dimiliki oleh bank maupun dana yang dapat dikumpulkan oleh masyarakat. Menurut Achmad (2003) bila jumlah kredit yang diberikan lebih kecil dari dana yang terhimpun, maka kelebihan dana dapat ditempatkan pada hal lain yang berguna dengan resiko lebih kecil. Loan Deposit Ratio (LDR) mencerminkan kemampuan bank dalam membayar kembali penarikan dana yang dilakukan deposan dengan mengandalkan kredit yang diberikan sebagai sumber likuiditasnya, dengan kata lain seberapa jauh pemberian kredit kepada nasabah kredit dapat mengimbangi kewajiban bank untuk segera memenuhi permintaan deposan yang ingin menarik kembali uangnya yang telah digunakan oleh bank untuk memberikan kredit yang diberikan dengan total dana pihak ketiga. Semakin tinggi nilai rasio Loan Deposit Ratio (LDR) menunjukkan semakin rendahnya kemampuan likuiditas bank yang bersangkutan sehingga kemungkinan suatu bank dalam kondisi bermasalah akan semakin besar, sebaliknya semakin rendah rasio Loan Deposit Ratio (LDR) menunjukkan kurangnya efektifitas bank dalam menyalurkan kredit sehingga hilangnya kesempatan bank untuk memperoleh laba.

H5: LDR berpengaruh terhadap Return On Asset (ROA)

\section{METODE PENELITIAN DAN ANALISIS DATA}

1. Objek Penelitian

Penelitian ini menggunakan data sekunder dari laporan keuangan Bank Perkreditan Rakyat di Salatiga yang terdaftar di Otoritas Jasa Keuangan (OJK) periode tahun 2011-2015 yang telah diaudit dan dipublikasi oleh umum. 


\section{Tabel 1}

Daftar nama BPR di Salatiga yang terdaftar di Otoritas Jasa Keuangan

(OJK)

\begin{tabular}{|c|l|}
\hline 1. & PT. BPR Satya Artha \\
\hline 2. & PT. Krida Harta Salatiga \\
\hline 3. & PT. BPR Dinamika Bangun Arta \\
\hline 4. & PD. BPR Bank Salatiga \\
\hline
\end{tabular}

2. Variabel Penelitian

Variabel dependen dalam penelitian ini adalah aspek profitabilitas yang diukur ROA. Sedangkan variabel yang diduga sebagai sebab di variabel independen dalam penelitian ini yaitu : CAR (Capital Adequacy Ratio), NPL (Non Performing Loan), BOPO (Biaya Operasional terhadap Pendapatan Operasional), NIM (Net Interest Margin), dan Loan Deposit Ratio (LDR).

a. Return On Assets (ROA)

ROA adalah perbandingan antara laba sebelum pajak dengan total aktiva bank. Menurut Bank Indonesia, perhitungan ROA sebagai beriku

$$
\mathrm{ROA}=\frac{\text { Laba Sebelum Pajak }}{\text { Rata }- \text { rata Total Aset }} \times 100 \% \ldots . . . . . . . .
$$

b. Capital Adequacy Ratio (CAR)

CAR adalah resiko kinerja bank untuk mengukur kecukupan modal yang dimiliki bank untuk menunjang aktiva yang mengandung dan menghasilkan risiko, misalnya kredit yang diberikan. Rasio CAR dapat di rumuskan sebagai berikut :

$$
\mathrm{CAR}=\frac{\text { Modal Bank }}{\text { Aktiva Tertimbang Menurut Risiko }} \times 100 \% \ldots \text { (2) }
$$

c. Non Performing Loan (NPL)

NPL merupakan ratio yang menunjukkan bahwa kemampuan manajemen bank dalam mengelola kredit bermasalah yang diberikan oleh bank. Rasio ini dapat diukur menggunakan rumus : 


$$
\text { NPL }=\frac{\text { Kredit Bermasalah }}{\text { Total Kredit }} \times 100 \% \ldots \text { (3) }
$$

d. BOPO

BOPO merupakan rasio biaya operasional adalah perbandingan antara

biaya operasional dan pendapatan operasional. Rasio ini dapat dirumuskan

$$
\mathrm{BOPO}=\frac{\text { Biaya }(\text { Beban }) \text { Operasional }}{\text { Pendapatan Operasional }} \times 100 \% \ldots \text { (4) }
$$

e. Net Interest Margin (NIM)

NIM yaitu rasio antara pendapatan bunga bersih dengan aktiva produktif suatu bank. NIM dapat dihitung menggunakan rumus :

$$
\mathrm{NIM}=\frac{\text { Pendapatan Bunga Bersih }}{\text { Aktiva Produktif }} \times 100 \% \ldots \text { (5) }
$$

\section{f. Loan to Deposit Ratio (LDR)}

LDR merupakan rasio yang digunakan untuk mengukur tingakat likuiditas bank yang menunjukkan kemampuan bank untuk memenuhi permintaan kredit dengan menggunakan total aset yang dimiliki bank. Rasio ini dapat dirumuskan sebagai berikut :

$$
\mathrm{LDR}=\frac{\text { Jumlah Kredit Yang Diberikan }}{\text { Jumlah Aset }} \times 100 \% \ldots \text { (6) }
$$

\section{Alat Analisis}

Teknik analisis yang akan dipakai dalam penelitian ini adalah teknik analisis regresi linier berganda untuk memperoleh gambaran yang menyeluruh mengenai hubungan antara variabel satu dengan variabel lain. Variabel dependen yang digunakan adalah Return on Asset (ROA) dan variabel independennya adalah Capital Adequacy Ratio (CAR), Non Performing Loan (NPL), Biaya Operasi dan Pendapatan Operasi (BOPO), Net Interest Margin (NIM) dan Loan to Deposit Ratio (LDR). Persamaan regresinya adalah sebagai berikut:

$$
\mathrm{ROA}=\alpha+\beta_{1} \mathrm{CAR}+\beta_{2} \mathrm{NPL}+\beta_{3} \mathrm{BOPO}+\beta_{4} \mathrm{NIM}+\beta_{5} \mathrm{LDR}+\varepsilon \mathrm{i}
$$


Di mana:

$\mathrm{ROA}=$ Return On Assets

CAR = Capital Adequacy Ratio

NPL = Non Performing Loan

$\mathrm{NIM}=$ Net Interest Margin

LDR = Loan to Deposit Ratio

\section{HASIL DAN PEMBAHASAN}

Regresi linier berganda adalah metode statistik yang digunakan untuk menguji pengaruh dua atau lebih variabel bebas terhadap variabel terikat dengan skala pengukuran interval atau rasio dalam persamaan linier. Berdasarkan perhitungan persaman regresi antara CAR (X1), NPL (X2), BOPO (X3), NIM (X4) dan LDR (X5) terhadap ROA (Y) dengan menggunakan SPSS 18 diperoleh hasil sebagai berikut :

Tabel 2

Koefisien Regresi Berganda

Coefficients $^{\text {a }}$

\begin{tabular}{|c|c|c|c|c|c|c|}
\hline \multirow{2}{*}{\multicolumn{2}{|c|}{ Model }} & \multicolumn{2}{|c|}{$\begin{array}{c}\text { Unstandardized } \\
\text { Coefficients } \\
\end{array}$} & \multirow{2}{*}{$\begin{array}{c}\text { Standardized } \\
\text { Coefficients } \\
\text { Beta }\end{array}$} & \multirow[b]{2}{*}{$\mathrm{t}$} & \multirow[b]{2}{*}{ Sig. } \\
\hline & & B & Std. Error & & & \\
\hline & (Constant) & 57,485 & 20,145 & & 2,854 & ,013 \\
\hline & CAR &,- 050 & ,031 & $-1,255$ & $-1,613$ & , 129 \\
\hline & NPL &,- 259 & ,116 & $-2,230$ & $-2,223$ & ,043 \\
\hline & BOPO &,- 087 & ,015 &,- 802 & $-5,774$ & ,000 \\
\hline & NIM &, 064 & ,086 & ,111 & ,748 & ,467 \\
\hline & LDR &,- 229 &, 083 & $-1,156$ & $-2,752$ & ,016 \\
\hline
\end{tabular}

a. Dependent Variable: ROA

Berdasarkan tabel di atas diperoleh persamaan regresi berganda sebagai berikut :

$Y=57,485-0,050 X_{1}-0,259 X_{2}-0.087 X_{3}+0,064 X_{4}-0,229 X_{5}$

Hasil persamaan regresi berganda tersebut diatas memberikan pengertian sebagai berikut : 
a. Konstanta sebesar 57,845 bearti apabila CAR (X1), NPL (X2), BOPO (X3), NIM (X4) dan LDR (X5) = 0 maka besarnya variabel ROA sebesar 57,845 satuan.

b. $b_{1}$ (nilai koefisien regresi $X_{1}$ ) sebesar $-0,050$ ada pengaruh negatif antara CAR terhadap ROA, yang bearti jika CAR $\left(\mathrm{X}_{1}\right)$ meningkat satu satuan sedangkan variabel lainnya tetap atau konstant, maka ROA akan menurun 0,050 .

c. $b_{2}$ (nilai koefisien regresi $\mathrm{X}_{2}$ ) sebesar $-0,259$ ada pengaruh negatif antara NPL terhadap ROA, yang bearti jika NPL $\left(\mathrm{X}_{2}\right)$ meningkat satu satuan sedangkan variabel lainnya tetap atau konstan, maka ROA akan menurun 0,259 satuan.

d. $b_{3}$ (nilai koefisien regresi $\mathrm{X}_{3}$ ) sebesar $-0,087$ ada pengaruh negatif antara BOPO terhadap ROA, yang bearti jika BOPO $\left(\mathrm{X}_{3}\right)$ meningkat satu satuan sedangkan variabel lainnya tetap atau konstan, maka ROA akan menurun 0,087 satuan.

e. $\mathrm{b}_{4}$ (nilai koefisien regresi $\mathrm{X}_{4}$ ) sebesar 0,064 ada pengaruh positif antara NIM terhadap ROA, yang bearti jika NIM $\left(\mathrm{X}_{4}\right)$ meningkat satu satuan sedangkan variabel lainnya tetap atau konstan, maka ROA akan meningkat 0,064 satuan.

f. $b_{5}$ (nilai koefisien regresi $X_{5}$ ) sebesar $-0,229$ ada pengaruh negatif antara LDR terhadap ROA, yang bearti jika LDR $\left(\mathrm{X}_{5}\right)$ meningkat satu satuan sedangkan variabel lainnya tetap atau konstan, maka ROA akan menurun 0,050 satuan.

Uji t digunakan untuk mengetahui ada tidaknya pengaruh signifikan antara CAR (X1), NPL (X2), BOPO (X3), NIM (X4) dan LDR (X5) terhadap ROA (Y).

Pengujian pertama dilakukan terhadap variabel CAR dengan ROA diperoleh nilai thitung -1,613 (Sig.0,129). Sedangkan nilai t tabel untuk degree of freedom $(\mathrm{df})=$ 14, level of significance $(\alpha / 2)$ 0,025 adalah 2,145 sehingga t hitung $=-1,613>$ daripada nilai $\mathrm{t}$ tabel $=-2,145$ dan nilai signifikansi $0,129>0,05$. Hal ini menunjukkan bahwa tidak terdapat pengaruh yang signifikan antara CAR terhadap ROA. 
Pengujian kedua dilakukan terhadap variabel NPL dengan ROA diperoleh nilai $\mathrm{t}$ hitung -2,230 (Sig.0,043). Sedangkan nilai t tabel untuk degree of freedom $(\mathrm{df})=14$, level of significance $(\alpha / 2) 0,025$ adalah 2,145 sehingga $t$ hitung $=-2,230<$ daripada nilai $\mathrm{t}$ tabel $=-2,145$ dan nilai signifikansi $0,043<0,05$. Hal ini menunjukkan bahwa terdapat pengaruh yang signifikan antara NPL terhadap ROA.

Pengujian ketiga dilakukan terhadap variabel BOPO dengan ROA diperoleh nilai thitung $-5,774$ (Sig.0,000). Sedangkan nilai t tabel untuk degree of freedom $(\mathrm{df})=$ 14 , level of significance $(\alpha / 2) 0,025$ adalah 2,145 sehingga t hitung $=-5,774<$ daripada nilai $\mathrm{t}$ tabel $=-2,145$ dan nilai signifikansi $0,000<0,05$. Hal ini menunjukkan bahwa terdapat pengaruh yang signifikan antara BOPO terhadap ROA.

Pengujian keempat dilakukan terhadap variabel NIM dengan ROA diperoleh nilai t hitung 0,78 (Sig.0,467). Sedangkan nilai t tabel untuk degree of freedom $(\mathrm{df})=$ 14 , level of significance $(\alpha / 2) 0,025$ adalah 2,145 sehingga t hitung $=0,748<$ daripada nilai $\mathrm{t}$ tabel $=2,145$ dan nilai signifikansi $0,467>0,05$. Hal ini menunjukkan bahwa tidak terdapat pengaruh yang signifikan antara NIM terhadap ROA.

Pengujian kelima dilakukan terhadap variabel LDR dengan ROA diperoleh nilai thitung -2,752 (Sig.0,016). Sedangkan nilai t tabel untuk degree of freedom $(\mathrm{df})=$ 14 , level of significance $(\alpha / 2)$ 0,025 adalah 2,145 sehingga t hitung $=-2,752<$ daripada nilai $\mathrm{t}$ tabel $=-2,145$ dan nilai signifikansi $0,016<0,05$. Hal ini menunjukkan bahwa terdapat pengaruh yang signifikan antara LDR terhadap ROA.

Uji F digunakan untuk mengetahui ada tidaknya pengaruh signifikan antara CAR (X1), NPL (X2), BOPO (X3), NIM (X4) dan LDR (X5) secara simultan berpengaruh terhadap ROA (Y).

\section{Tabel 3}

\section{Hasil Uji F}

\begin{tabular}{|c|c|c|c|c|c|c|}
\hline \multicolumn{7}{|c|}{ ANOVA $^{b}$} \\
\hline \multicolumn{2}{|c|}{ Model } & Sum of & & Mean & & \\
\hline \multirow[t]{3}{*}{1} & Regression & 47,151 & 5 & 9,430 & 10,824 &, $000^{\mathrm{a}}$ \\
\hline & Residual & 12,197 & 14 & ,871 & & \\
\hline & Total & 59,348 & 19 & & & \\
\hline
\end{tabular}

a. Predictors: (Constant), LDR, BOPO, NIM, CAR, NPL

b. Dependent Variable: ROA 
Nilai F hitung sebesar 10,824 (Sig.0,000) sedangkan nilai F tabel dengan degreeof freedom (df) pada angka 5 dan 14, level significance 0,05 sebesar 2,39 sehingga nilai $\mathrm{F}$ hitung $=10,824$ jauh lebih besar daripada $\mathrm{F}$ tabel 2,96 dan signifikansi $(0,000)$ lebih kecil dari 0,05 maka model regresi dapat digunakan untuk memprediksi variabel ROA atau dapat dikatakan bahwa tingkat CAR (X1), NPL (X2), BOPO (X3), NIM (X4) dan LDR (X5) secara bersama-sama berpengaruh terhadap ROA (Y).

Koefisien determinasi yang digunakan adalah nilai Adjusted $R^{2}$ karena koefisien determinasi memiliki kelemahan mendasar dalam menerangkan variasi variabel dependen, yaitu bias terhadap jumlah variabel independen yang dimasukkan ke dalam model. Setiap tambahan satu variabel independen, maka Adjusted $R^{2}$ pasti meningkat tidak peduli apakah variabel tersebut berpengaruh secara signifikan terhadap variabel terhadap variabel dependen atau tidak.

Tabel 4

Koefisien Determinasi

\begin{tabular}{|l|c|r|r|r|}
\hline Model & R & R Square & Adjusted R Square & Std. Error of the Estimate \\
\hline 1 &, $891^{\mathrm{a}}$ &, 794 &, 721 &, 93341 \\
& & & & \\
& & & & \\
& & & & \\
\hline
\end{tabular}

a. Predictors: (Constant), LDR, BOPO, NIM, CAR, NPL

b. Dependent Variable: ROA

Dari Output SPSS dihasilkan besar Adjusted $R^{2}$ adalah 0,721 , hal ini bearti $72,1 \%$ variasi variabel dependen (ROA) bisa dijelaskan oleh variasi dari kelima variabel independen tingkat CAR (X1), NPL (X2), BOPO (X3), NIM (X4) dan LDR (X5). Sedangkan sisanya $(100 \%-72,1 \%=27,9 \%)$ dijelaskan oleh variabel lainnya diluar model. 


\section{KESIMPULAN DAN SARAN}

\section{Kesimpulan}

Penelitian ini membahas tentang pengaruh CAR, NPL, BOPO, NIM dan LDR terhadap ROA. Berdasarkan uraian-uraian pada bab sebelumnya penulis mengambil kesimpulan sebagai berikut :

1. Terdapat pengaruh yang signifikan antara CAR (X1), NPL (X2), BOPO (X3), NIM (X4) dan LDR (X5) terhadap ROA (Y) secara individual. Hal ini dibuktikan dari :

a. Pengujian pertama dilakukan terhadap variabel CAR dengan ROA diperoleh nilai t hitung -1,613 (Sig.0,129). Sedangkan nilai t tabel untuk degree of freedom $(\mathrm{df})=14$, level of significance $(\alpha / 2) 0,025$ adalah 2,145 sehingga $\mathrm{t}$ hitung $=-1,613>$ daripada nilai $\mathrm{t}$ tabel $=-2,145$ dan nilai signifikansi $0,129>0,05$. Hal ini menunjukkan bahwa tidak terdapat pengaruh yang signifikan antara CAR terhadap ROA. Dengan demikian dapat disimpulkan bahwa Ho diterima dan Ha ditolak artinya hipotesis yang menyatakan terdapat pengaruh yang signifikan antara CAR terhadap ROA dapat diterima.

b. Pengujian kedua dilakukan terhadap variabel NPL dengan ROA diperoleh nilai t hitung -2,230 (Sig.0,043). Sedangkan nilai t tabel untuk degree of freedom $(\mathrm{df})=14$, level of significance $(\alpha / 2)$ 0,025 adalah 2,145 sehingga $\mathrm{t}$ hitung $=-2,230<$ daripada nilai $\mathrm{t}$ tabel $=-2,145$ dan nilai signifikansi $0,043<0,05$. Hal ini menunjukkan bahwa terdapat pengaruh yang signifikan antara NPL terhadap ROA. Dengan demikian dapat disimpulkan bahwa Ho ditolak dan Ha diterima artinya hipotesis yang menyatakan terdapat pengaruh yang signifikan antara NPL terhadap ROA dapat diterima.

c. Pengujian ketiga dilakukan terhadap variabel BOPO dengan ROA diperoleh nilai t hitung -5,774 (Sig.0,000). Sedangkan nilai t tabel untuk degree of freedom $(\mathrm{df})=14$, level of significance $(\alpha / 2) 0,025$ adalah 2,145 sehingga $\mathrm{t}$ hitung $=-5,774<$ daripada nilai $\mathrm{t}$ tabel $=-2,145$ dan nilai signifikansi $0,000<0,05$. Hal ini menunjukkan bahwa terdapat pengaruh yang signifikan antara BOPO terhadap ROA. Dengan demikian dapat 
disimpulkan bahwa Ho ditolak dan Ha diterima artinya hipotesis yang menyatakan terdapat pengaruh yang signifikan antara BOPO terhadap ROA dapat diterima.

d. Pengujian keempat dilakukan terhadap variabel NIM dengan ROA diperoleh nilai t hitung 0,78 (Sig.0,467). Sedangkan nilai t tabel untuk degree of freedom $(\mathrm{df})=14$, level of significance $(\alpha / 2) 0,025$ adalah 2,145 sehingga $\mathrm{t}$ hitung $=0,748<$ daripada nilai $\mathrm{t}$ tabel $=2,145$ dan nilai signifikansi $0,467>0,05$. Hal ini menunjukkan bahwa tidak terdapat pengaruh yang signifikan antara NIM terhadap ROA. Dengan demikian dapat disimpulkan bahwa Ho diterima dan Ha ditolak artinya hipotesis yang menyatakan terdapat pengaruh yang signifikan antara NIM terhadap ROA dapat diterima.

e. Pengujian kelima dilakukan terhadap variabel LDR dengan ROA diperoleh nilai t hitung -2,752 (Sig.0,016). Sedangkan nilai t tabel untuk degree of freedom $(\mathrm{df})=14$, level of significance $(\alpha / 2) 0,025$ adalah 2,145 sehingga $t$ hitung $=-2,752<$ daripada nilai $\mathrm{t}$ tabel $=-2,145$ dan nilai signifikansi $0,016<0,05$. Hal ini menunjukkan bahwa terdapat pengaruh yang signifikan antara LDR terhadap ROA. Dengan demikian dapat disimpulkan bahwa Ho ditolak dan Ha diterima artinya hipotesis yang menyatakan terdapat pengaruh yang signifikan antara LDR terhadap ROA dapat diterima.

2. Berdasarkan pengujian simultan nilai $\mathrm{F}$ hitung sebesar 10,824 (Sig.0,000) sedangkan nilai $\mathrm{F}$ tabel dengan degreeof freedom (df) pada angka 5 dan 14, level significance 0,05 sebesar 2,39 sehingga nilai $\mathrm{F}$ hitung $=10,824$ jauh lebih besar daripada $\mathrm{F}$ tabel 2,96 dan signifikansi $(0,000)$ lebih kecil dari 0,05 maka model regresi dapat digunakan untuk memprediksi variabel ROA atau dapat dikatakan bahwa tingkat CAR (X1), NPL (X2), BOPO (X3), NIM (X4) dan LDR (X5) secara bersama-sama berpengaruh terhadap ROA (Y). Dengan demikian dapat disimpulkan Ho ditolak Ha diterima.

3. Koefisien Determinan diperoleh sebesar $72,1 \%$ dari Output SPSS dihasilkan dari nilai Adjusted $R^{2}$, hal ini bearti $72,1 \%$ dapat dijelaskan oleh variasi kelima 
variabel independen CAR, NPL, BOPO, NIM dan LDR. Sedangkan sisanya $27,9 \%$ dipengaruhi oleh oleh faktor lain yang tidak diteliti.

\section{Saran}

Berdasarkan kesimpulan atas hasil penelitian mengenai pengaruh CAR, NPL, BOPO, NIM dan LDR terhadap ROA, maka saran yang bisa diajukan peneliti sebagai berikut :

1. Perlunya mengambil kebijakan agar kinerja dapat ditingkatkan dengan menerapkan Manajemen Resiko secara konsisten dan konsekuen agar bisa menekan tingginya tingkat Non Performing Loan (NPL), Misal lebih jeli menyalurkan kredit kepada nasabah, memantau secara benar di lapangan tentang penggunaan kredit, melakukan pengecekan tentang kondisi sebenarnya calon nasabah di lapangan dan memperhitungkan cash flow dari kredit yang disalurkan.

2. Penanganan secara khusus terhadap kredit yang bermasalah agar bisa meningkatkan perolehan laba.

3. Penambahan produk baru juga penting karena dapat memberikan kontribusi laba.

4. Perlunya pelatihantenaga kerja secara menyeluruh agar bisa memahami dan menjalankan tugas tugas dalam perbankan sesuai dengan aturan dan kondisi yang sedang terjadi. 


\section{DAFTAR PUSTAKA}

Achmad, S. 2003. Ekonomi Perbankan. Jakarta: STIE Gunadarma.

Ali, Masyhud, 2004, Asset Liability Management : Menyiasati Risiko Pasar dan Risiko Operasional, PT Gramedia Jakarta.

Almilia, Luciana Spica dan Herdiningtyas, Winny, 2005, "Analisis Rasio Camel Terhadap Prediksi Kondisi Bermasalah Pada Lembaga Perbankan Perioda 2000-2002”, Jurnal Akuntansi \& Keuangan, Vol.7, No.2, Hal.131-147.

Admosudirdjo, Prayudi, 1979, Sistem Pelayanan Publik, Jakarta : Bina Cipta

Darminto, Dwi Prastowo dan Rifka Julianty, 2002, "Kinerja Keuangan Bank-bank Beku Operasi, Rekapitalisasi, dan Sehat Tahun 1992-1998”, Ventura, Vol.4, No,2, September, pp.97-107.

Dendawijaya. Lukman. 2000. Manajemen Perbankan. Ghalia Indonesia, Jakarta.

Ghozali, 2007, Manajemen Risiko Perbankan Pendekatan VaR, Badan Penerbit Universitas Diponegoro, Semarang.

Husnan, Suad, 2004, Manajemen Keuangan - Teori dan Penerapan, Buku 2, BPFE Yogyakarta.

Januarti, Indira, 2002, “ Variabel Proksi CAMEL dan Karakteristik Bank Lainnya untuk Memprediksi Kebangkrutan Bank Indonesia", Jurnal Bisnis Strategi, Vol. 10, Desember, pp.1-10.

Kasmir dkk, 2000, Fungsi-fungsi Kredit, Bandung : Angkasa

Kasmir, 2010, Dasar-dasar Perbankan, Jakarta : PT Raja Grafindo.

Koch, Timothy W \& S. Scott MacDonald, 2000, Bank Management, 4th Edition, Harcout College Publishers, New York.

Kusumaningrum, Canda, 2010. Faktor-faktor Yang Mempengaruhi Profitabilitas Perbankan di Bank Daerah Tahun 2003-2008, Semarang : Universitas Diponegoro.

Mawardi, Wisnu, 2005, "Analisis Faktor-faktor yang Mempengaruhi Kinerja Keuangan Bank Umum di Indonesia (Studi Kasus pada Bank Umum dengan Total Asset Kurang dari 1 Triliun)", Jurnal Bisnis Strategi, Vol.14, No.1, Juli, pp.83-94.

Moekijat 1988, Sistem Informasi Manajemen, Bandung : CV Satria.

Analisis Pengaruh CAR, NPL, BOPO, NIM

dan LDR Terhadap ROA (Studi Kasus Pada Bank Perkreditan Rakyat di Salatiga

yang Terdaftar Di Otoritas Jasa Keuangan Tahun 2011-2015).

(Erna Sudarmawanti, Joko Pramono) 
Muljono, Teguh Pudjo, 1999, Aplikasi Akuntansi Manajemen Dalam Praktik Perbankan, Edisi 3, BPFE Yogyakarta.

Mulyana dan Teguh P, 1986, Kredit Lembaga Perbankan, Jakarta : STIE Perbanas.

Nugroho, Agung, 2001, Analisis Faktor-faktor Yang Mempengaruhi Keputusan Pemberian Kredit pada BPR di Kota Semarang, semarang : STIE BPD.

Peraturan Bank Indonesia No.5/ 8/ PBI/ 2003, Penerapan Manajemen Risiko bagi Bank Umum.

Riahi-Belkaoui, Ahmed., Picur, Ronald D, 1998, Multinationality and Profitability : The Contingency of the Investmen Opportunity Set, Journal of Management Finance, Vol.24, pp.3-14.

Sampurno, R. Joko, 2011. Analisis Pengaruh CAR, NPLdan NIP terhadap ROA Bank Swasta Nasional Devisa dan Bank Swasta Nasional Non Devisa Periode Tahun 2004- 2008 Salatiga

Sri Haryati , 2001. Analisis Kebangkrutan Bank, Bunga Rampai Kajian Teori Keuangan In Memoriam Prof. Dr, Bambang Riyanto. Fakultas Ekonomi Universitas Ekonomi Yogyakarta.

Surat Edaran Bank Indonesia No 6/73/Intern DPNP tanggal 24 Desember 2004, Perihal Pedoman Sistem Penilaian Tingkat Kesehatan Bank Umum (CAMELS Rating, Bank Indonesia, Jakarta.

Tainio, Risto, Pekka J. Korhonen, Timo J, Santalainen, 2000, In Search of Explanation for Bank Performance - Some Finnish Data, Organization Studies, 12/3. P : 425-450

UU No 10 Tahun 1998 tentang Perbankan

UU No 7 Tahun 1992 tentang Perbankan 